\title{
Antagonistic Drug-herb Interactions between Clinacanthus nutans and Cyclophosphamide on WRL 68 Cell Line
}

\author{
Nurliana Abd Mutalib, Normala Abd Latip* \\ Faculty of Pharmacy, Universiti Teknologi MARA Cawangan Selangor, 43200, Puncak Alam, Selangor, Malaysia
}

\begin{abstract}
Clinacanthus nutans (Acanthaceae), locally known as Sabah snake grass, is popularly taken as prevention as well as treatment for cancer in Malaysia, despite lack of concrete clinical evidence. However, it is crucial to evaluate potential antagonistic, additive, or synergistic interactions that may result from the co-treatment of this plant in chemotherapy. In this study, we demonstrate the drug-herb interaction using combination treatment of $C$. nutans extracts and cyclophosphamide on the WRL 68 cell line. Materials and Methods: Aqueous and 70\% ethanol extract of $C$. nutans leaves were prepared using decoction and maceration methods. MTT assay was used to test single treatment as well as the combination of $C$. nutans extract and cyclophosphamide. Phytochemical profiling and flavonoid were identified using HPLC. Results: C. nutans ethanolic extract exhibits low antiproliferative activity. A combination of ethanolic extract of C. nutans and cyclophosphamide at various concentrations resulted in antagonism with combination index values of $1.413,1.482$, and 1.525. Flavonoids identified in the phytochemical profile of both extracts were schaftoside, isoorientin, orientin, and vitexin. High flavonoids level in C. nutans ethanolic extract could potentially interact with metabolic enzymes of the cell line, which might have affected metabolism and activated the cyclophosphamide. The in vitro data suggested that there was a potential for drug-herb interactions, which could negatively affect the chemotherapeutic outcomes. Further investigation should be done in vivo and clinical research model.
\end{abstract}

Keywords: Clinacanthus nutans; cyclophosphamide; drug-herb interactions; isobologram; combination index

*corresponding author

Email: drnormala6351@puncakalam.uitm.edu.my

\section{INTRODUCTION}

Botanical medicine or phytomedicine, commonly known as herbal medicine, serves medicinal and therapeutic purposes by utilizing parts of plants such as leaves, roots, seeds, flowers, berries, or bark (Chikezie \& Ojiako, 2015). In almost every culture worldwide, including America, Europe, Africa, and also Asia, herbal plants have played a vital role as medications (Wargovich et al., 2001). Herbal remedies are mostly promoted as natural and harmless thus, many countries do not have regulations that demand the demonstration of its therapeutic efficacy, safety, or quality (Fasinu et al., 2012). However, previous studies revealed that drug-herbal medicine interactions could reduce efficacy or cause failure in drug treatment, such as chemotherapy treatments. Therapeutic failure is common in chemotherapy treatment as the effects of herbal medicine, for example, metabolism induction, usually lead to lower plasma levels due to the inactivation of the chemotherapy drug (Meijerman et al., 2006).

Drug-herb interactions may provide benefits in cancer treatment, such as reducing adverse side effects (Desai et al., 2008). However, the potentially harmful effects that may arise from interactions between complementary herbal medicine and conventional drugs are undeniable. Consumption of herbs concomitantly with conventional drugs has become the norm that promoting the potential of pharmacokinetic or pharmacodynamic drug-herb interactions as the combination may mimic, increase or reduce the effects of the drug or the herb which could result in clinically significant interactions ( $\mathrm{Hu}$ et al., 2005).

Cancer patients tend to use the herbal supplement as complementary treatments and to reduce symptoms. A survey conducted in a Malaysian tertiary hospital revealed that $51.6 \%$ of 103 breast cancer patients use Malay traditional/folk medicine, and $34.1 \%$ of them use herbs as complementary and alternative medicine (RajaLexshimi et al., 2013). The patients who self- medicate with herbs also given chemotherapy drug and drug-herb interactions are typical, which may lead to problems. Cyclophosphamide is one of the most successful anticancer agents that is used in combination with other antineoplastic agents for the treatment of various cancers, including breast, lymphoid and pediatric malignancies (Emadi et al., 2009). This is an alkylating 
agent and undergoes metabolism by two different cytochrome $\mathrm{P} 450$ pathways, which are 4-hydroxylation, the activation pathway, and N-dechloroethylation, the inactivation pathway of the drug (Chen et al., 2004).

Clinacanthus nutans locally known as Sabah Snake grass, or "Belalai Gajah" is a small shrub classified under the family of Acanthaceae. Various kinds of C. nutans products are available in the market, and this plant is usually consumed as herbal tea in Malaysia (Alam et al., 2016). This plant exhibits antiviral, anti-inflammatory, antioxidant, as well as anticancer properties (Chin et al., 2014). C. nutans has been widely used as an anticancer remedy without knowing its effects on chemotherapy. A recent study found that methanol extract of $C$. nutans at different concentrations possesses inhibitory activity on the metabolism of an analgesic drug (aminopyrine) by CYP3A4 (Quah et al., 2017). In this study, polar extracts of $C$. nutans were evaluated for their phytochemical profiles, antiproliferative activity, and also combination effect with cyclophosphamide on the normal liver cell line.

\section{METHODS}

\section{Extraction of Clinacanthus nutans}

Dried C. nutans leaves powder was bought from a nursery located in Kota Bharu, Kelantan andwas extracted according to the method described previously with slight modifications (Quah et al., 2017). For ethanolic extract, $50 \mathrm{mg}$ of a powder sample in $500 \mathrm{~mL}$ of $70 \%$ ethanol was sonicated for $30 \mathrm{~min}$. The solvent was then removed using a rotary evaporator at $40{ }^{\circ} \mathrm{C}$. For aqueous extraction, a slightly modified method described before was used (Al-Manhel et al., 2015). $100 \mathrm{~g}$ of powdered sample was boiled in $200 \mathrm{~mL}$ of water for 20,30 , and 60 $\mathrm{min}$. The extract then allowed to cool at room temperature for one hour before vacuum filtered using Whatman No. 1 filter paper. The supernatant of aqueous extract and residue of ethanolic extract after solvent removal were frozen at $-80{ }^{\circ} \mathrm{C}$ and lyophilized using a freeze dryer on the next day (Bohlooli et al., 2012). Dried extract residue kept at $-20{ }^{\circ} \mathrm{C}$ until further analysis. The extraction yield of each extract was calculated using equation (1).

Percentage extraction yield $=($ mass of extract $/$ mass of sample $) \times 100$

Table 1. The percent yield of extraction of $C$. nutans aqueous extracts and ethanolic extract

\begin{tabular}{|c|c|c|}
\hline Extract code & Extract & $\begin{array}{l}\% \quad \text { yield } \\
\text { of extraction }\end{array}$ \\
\hline A & Aqueous, decoction, $100^{\circ} \mathrm{C}, 20 \mathrm{~min}$ & $2.92 \%$ \\
\hline B & Aqueous, decoction, $100^{\circ} \mathrm{C}, 30 \mathrm{~min}$ & $3.56 \%$ \\
\hline $\mathbf{C}$ & Aqueous, decoction, $100^{\circ} \mathrm{C}, 60 \mathrm{~min}$ & $4.42 \%$ \\
\hline D & $70 \%$ ethanol, sonication, $30 \mathrm{~min}$ & $5.81 \%$ \\
\hline
\end{tabular}

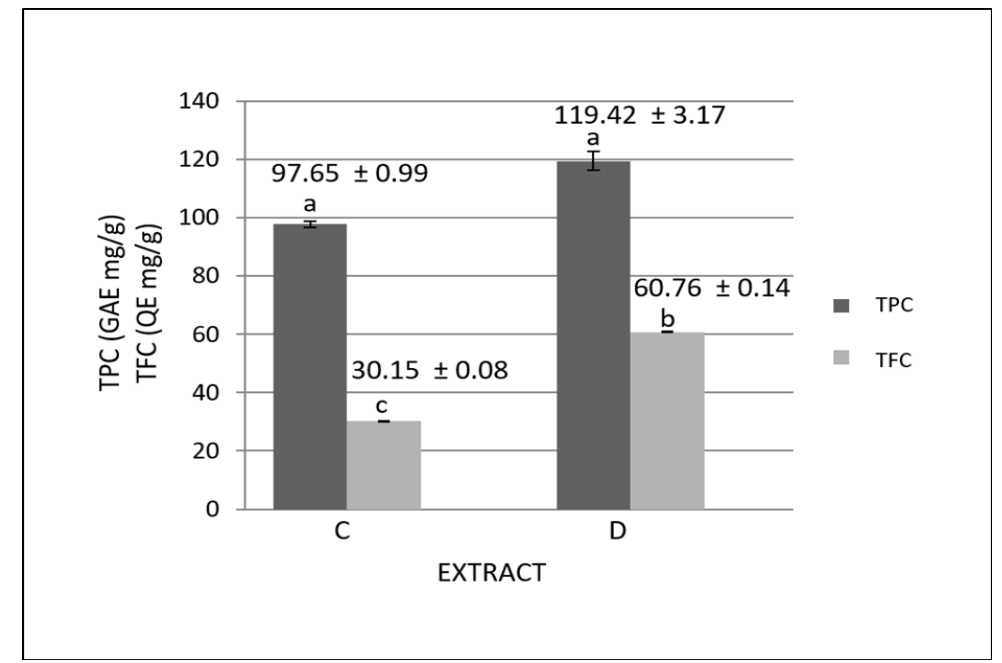

Figure 1. Total phenolic content, TPC (mean \pm SEM) and total flavonoid content, TFC (mean \pm SEM) of $C$. nutans aqueous (C), and ethanolic (D) extracts. Bars with different letters denoted that the mean values were significantly different between extracts (t-test, $\mathrm{p}<\mathbf{0 . 0 5}$ ). 
Table 2. $\mathrm{IC}_{10}, \mathrm{IC}_{15}, \mathrm{IC}_{25}$, and $\mathrm{IC}_{50}$ of $C$.nutans ethanolic extract on WRL 68

\begin{tabular}{lllll}
\hline Treatment & $\begin{array}{l}\mathbf{I C}_{10} \\
(\text { mean } \pm \text { SEM) }\end{array}$ & $\begin{array}{l}\mathbf{I C}_{15} \\
(\text { mean } \pm \text { SEM) }\end{array}$ & $\begin{array}{l}\mathbf{I C}_{25} \\
(\text { mean } \pm \text { SEM })\end{array}$ & $\begin{array}{l}\mathbf{I C}_{50} \\
(\text { mean } \pm \text { SEM })\end{array}$ \\
\hline $\begin{array}{l}\text { C. nutans ethanolic } \\
\text { extract }(\mathrm{mg} / \mathrm{mL})\end{array}$ & $1.223 \pm 0.016$ & $1.634 \pm 0.014$ & $2.354 \pm 0.006$ & $4.051 \pm 0.041$ \\
& & & & \\
\hline
\end{tabular}

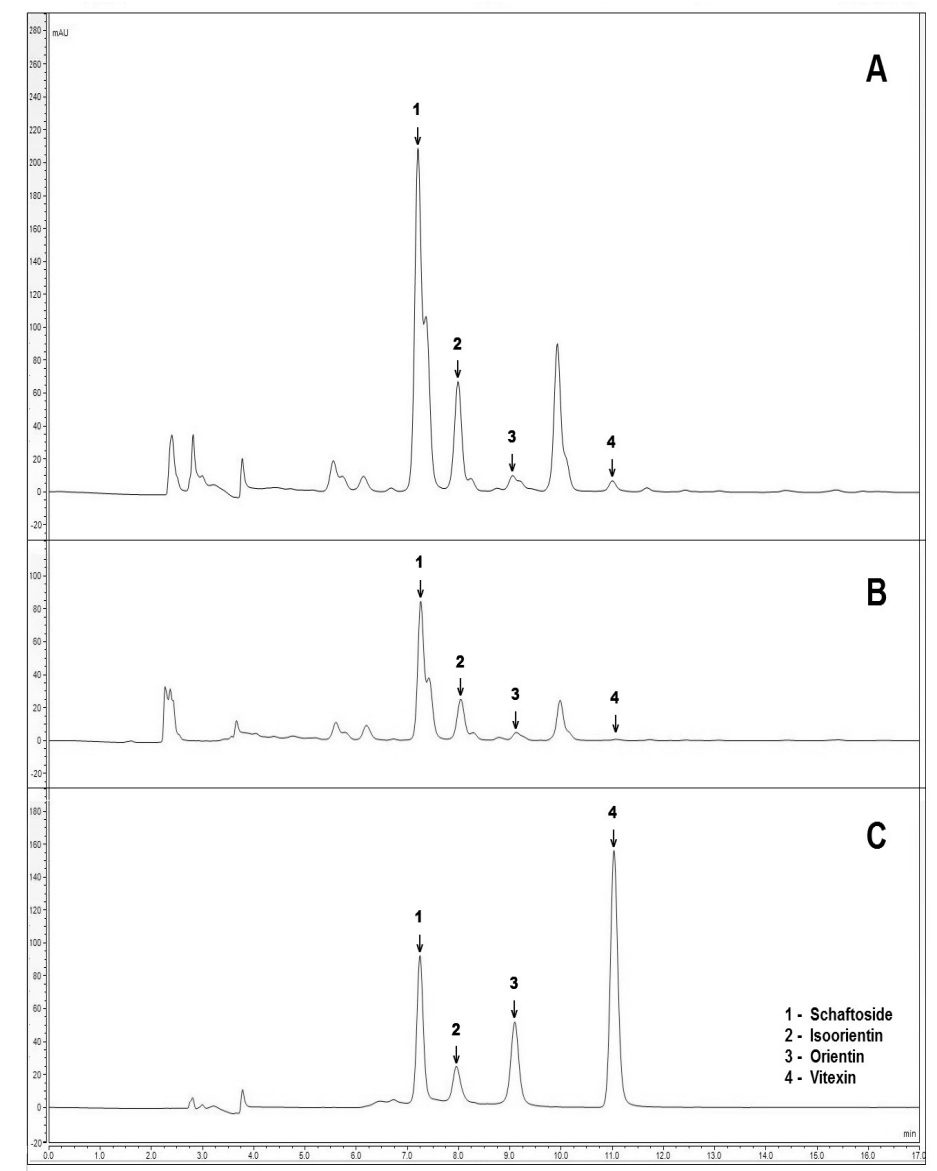

Figure 2. HPLC Chromatograms of A: Ethanolic extract (D) profile, B: Aqueous extract (C) profile and C: Flavonoid standards (schaftoside, isoorientin, orientin, and vitexin)

\section{Total Phenolic Content}

The total phenolic content of the extracts was quantified using the Folin-Ciocalteu reagent (Aziz \& Jack, 2015). $10 \mathrm{mg}$ of dried extracts were dissolved in $1 \mathrm{~mL}$ of water and vortexed until homogenous. $1 \mathrm{~mL}$ of Folin-Ciocalteu reagent and $0.8 \mathrm{~mL}$ of $7.5 \%(\mathrm{w} / \mathrm{v})$ sodium bicarbonate $\left(\mathrm{Na}_{2} \mathrm{CO}_{3}\right)$ were added to $0.2 \mathrm{~mL}$ of extract. The mixture was incubated for 1 hour at room temperature $\left(25-27^{\circ} \mathrm{C}\right)$. The absorbance at $760 \mathrm{~nm}$ was measured using a UVVis spectrophotometer. The six-point calibration curve was plotted with six concentrations of gallic acid (0.02 to $0.30 \mathrm{mg} / \mathrm{mL}$ ).

\section{Total Flavonoid Content}

A method described previously was used with slight modification (Kalita et al., 2013). Extracts were prepared at concentration $1 \mathrm{mg} / \mathrm{mL}$ in methanol. $500 \mu \mathrm{L}$ of extract stock, $1.5 \mathrm{ml}$ methanol, $100 \mu \mathrm{L} 1 \%$ aluminum chloride, $100 \mu \mathrm{L} 1 \mathrm{M}$ potassium acetate solution, and $2.8 \mathrm{ml}$ distilled water were mixed in 6 well-plates. Absorbance was measured at $415 \mathrm{~nm}$ after $30 \mathrm{~min}$, incubation at room temperature. The calibration curve of quercetin at $20,40,60,80$, and $100 \mu \mathrm{g} / \mathrm{mL}$ was plotted. 


\section{HPLC Analysis}

Prior to analysis, $1 \mathrm{mg}$ of $C$. nutans extract was dissolved in $1 \mathrm{~mL}$ HPLC grade methanol and filtered through a PTFE filter (pore size, $0.22 \mu \mathrm{m}$ ). For the extract phytochemicals profiling, HPLC conditions described in a previous study was used with modifications (Chelyn et al., 2014). Extracts were analyzed using Dionex Ultimate 3000 HPLC systems equipped with a Diode Array Detector (Thermo Fisher Scientific Inc., MA, USA). Separations were performed on a reversephase Luna C18 $(150 \times 4.6 \mathrm{~mm}$ i.d., $5 \mu \mathrm{m}$ particle size $)$ analytical column (Phenomenex, Torrance, CA, USA). Separation operated at a column oven temperature of $28^{\circ} \mathrm{C}$ at a flow rate of $0.6 \mathrm{~mL} / \mathrm{min}$. The mobile phases " $\mathrm{A}$ " and "B" are water and acetonitrile, respectively. A $10 \mu \mathrm{L}$ injection volume was injected and elution gradient for the separation as follows: initial $17 \% \mathrm{~B}, 0-12 \mathrm{~min}, 17-$ $25 \% \mathrm{~B}$; $12-14 \mathrm{~min}, 25 \% \mathrm{~B}$; 14-15 min, 25-17\% B; 15-17 min, $17 \%$ B. Detection was carried out at a wavelength of $360 \mathrm{~nm}$. All samples were injected triplicate.

\section{Cell Culture}

A method described previously was used for cell culture procedure ( $\mathrm{Su}$ et al., 2016). WRL 68, HaCaT, and CRL2522 cell lines were cultured in DMEM while
MCF-7 was cultured in RPMI media, and both media supplemented with 5\% FBS, $100 \mu \mathrm{M}$ streptomycins, and $100 \mathrm{U} / \mathrm{mL}$ penicillin. The culture condition is a humidified atmosphere of $95 \%$ air plus $5 \% \mathrm{CO}_{2}$ in a $37^{\circ} \mathrm{C}$ incubator. Cell count performed using a protocol described by Cadena-Herrera et al. (2015).

\section{MTT Assay}

This assay was conducted following the method described previously with modifications (Norfazlina et al., 2014). After seeding $5 \times 10^{3}$ cells per well and incubation for 24 hours, 90\% confluence cell culture in 96 wellplates was treated with $100 \mu \mathrm{L}$ of extracts at different concentration $(0-5 \mathrm{mg} / \mathrm{ml})$ and positive control (cisplatin at $0.25 \mathrm{mM}$ ). After incubation at $37^{\circ} \mathrm{C}$ for 24 hours, 20 $\mu \mathrm{L}$ MTT solution was added into each well and put in the incubator for 4 hours. After incubation with DMSO to stop the reaction, the absorbance value was measured using a microplate reader at $570 \mathrm{~nm}$. This assay was repeated with cyclophosphamide treatment at different concentrations (0-50 mM). The assay was also repeated with a combination of extract and cyclophosphamide on WRL 68 at a different ratio. $\mathrm{IC}_{50}$ and Combination Index (CI) values were calculated, and isobolograms were constructed.

Table 3. $\mathrm{IC}_{10}, \mathrm{IC}_{15}, \mathrm{IC}_{25}$, and $\mathrm{IC}_{50}$ of Cyclophosphamide on WRL 68

\begin{tabular}{lllll}
\hline Treatment & $\begin{array}{l}\text { IC }_{\mathbf{1 0}} \\
(\text { mean } \pm \text { SEM) }\end{array}$ & $\begin{array}{l}\text { IC }_{15} \\
(\text { mean } \pm \text { SEM) }\end{array}$ & $\begin{array}{l}\text { IC }_{25} \\
(\text { mean } \pm \text { SEM) }\end{array}$ & $\begin{array}{l}\text { IC }_{\text {50 }} \\
\text { (mean } \pm \text { SEM) }\end{array}$ \\
\hline Cyclophosphamide & $0.264 \pm 0.053$ & $0.668 \pm 0.105$ & $2.156 \pm 0.216$ & $10.525 \pm 0.244$ \\
$(\mathbf{m M})$ & & & & \\
\hline
\end{tabular}

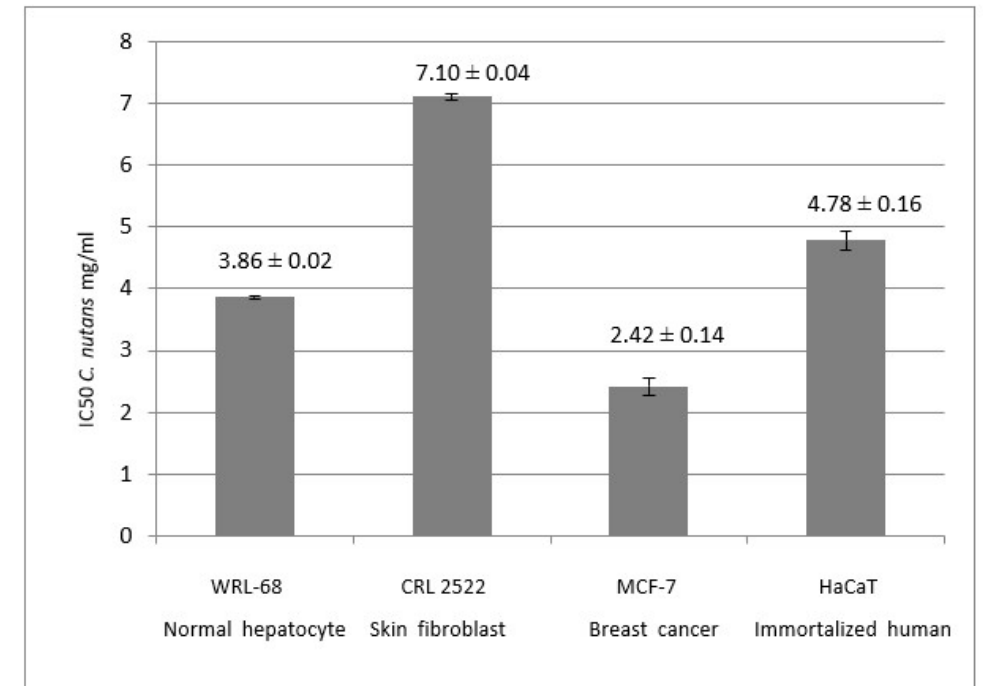

Figure 3. $\mathrm{IC}_{50}$ (mean $\pm \mathrm{SEM}$ ) of antiproliferative activity of $C$. nutans ethanolic extract against WRL 68, CRL 2522, MCF7, and $\mathrm{HaCaT}$ cell lines. Bars with different letters denoted that the $\mathrm{IC}_{50}$ values were significantly different between cell lines (one-way ANOVA, followed by posthoc Tukey's test, $p<0.05$ ) 


\section{RESULTS}

Aqueous and solvent extracts of $C$. nutans were produced, and the yield of extraction was calculated. The total phenolic content of the extracts was evaluated, and HPLC analysis of the extracts phytochemical profiles was conducted. The extraction yield of each extract was calculated, and the result tabulated in Table 1.

For aqueous extract, the effect of extraction time on the yield of extraction was evaluated. The result of Pearson's correlation analysis demonstrated a strong relationship between extraction time and extraction yield of $C$. nutans aqueous extract as the Pearson's $r$ value obtained was 0.981 . This analysis means changes in extraction time strongly correlated to changes in extraction yield. However, the correlation was not statistically significant because the $\mathrm{p}$-value was $0.125(\mathrm{p}>0.05)$, which means an increase or decrease in extraction time does not cause significant changes in extraction yield. In addition, the percent yield of the ethanolic extract was the highest among all samples, which was $5.82 \%$. It is crucial to point out that extraction methods do affect the phytochemical content in the extracts, such as phenolic compounds. Therefore, total phenolic content (TPC) and total flavonoid content (TFC) of the extracts $\mathrm{C}$ and D were evaluated, and the results demonstrated in Figure 1. Generally, gallic acid is used as the reference standard compound for TPC, and results are expressed as $\mathrm{mg}$ gallic acid equivalent (GAE $\mathrm{mg} / \mathrm{g})$. The concentration of total flavonoid content in the test samples was calculated from the calibration plot and expressed as mg quercetin equivalent $(\mathrm{QE} \mathrm{mg} / \mathrm{g})$. There is no significant difference in TPC of both extracts C and D. However, TFC of extract $\mathrm{D}$ is significantly higher than of extract $\mathrm{C}$.

HPLC profiling of aqueous extract (C) and ethanolic extract (D) was conducted. From the chromatograms in Figure 2, it showed that the phytochemical profiles of both aqueous and ethanolic extracts were qualitatively similar but quantitatively different in compositions. The amount of flavonoid compounds is lesser in aqueous extract (C) compared to in ethanolic extract (D).

Extract with the highest TPC and TFC, an ethanolic extract (D), was screened for its antiproliferative activity as preliminary evaluation. MTT assay was done to evaluate the antiproliferative effect of the extract against WRL 68 (normal liver), CRL2522 (normal fibroblast), MCF7 (breast cancer), and $\mathrm{HaCaT}$ (immortalized keratinocyte) cell lines. IC50 value of ethanolic extracts were $3.86 \pm 0.02 \mathrm{mg} / \mathrm{ml}, 7.10 \pm 0.04 \mu \mathrm{g} / \mathrm{ml}, 2.42 \pm 0.14$ $\mathrm{mg} / \mathrm{ml}$ and $4.78 \pm 0.16$, respectively, as summarized in Figure 3. The results were expressed as the median inhibitory concentration (IC50) mean \pm SEM.

Table 4. Combination index

\begin{tabular}{lllll}
\hline $\begin{array}{l}\text { Combination } \\
\text { Treatment }\end{array}$ & FIC CX & FIC CN & $\begin{array}{l}\text { Combination } \\
\text { Index (CI) }\end{array}$ & Description \\
\hline $\mathrm{CX}+\mathrm{CN} \mathrm{IC}_{10}$ & 0.841 & 0.684 & 1.525 & Antagonism \\
$\mathrm{CX}+\mathrm{CN} \mathrm{IC}_{15}$ & 0.741 & 0.741 & 1.482 & Antagonism \\
$\mathrm{CX}+\mathrm{CN} \mathrm{IC}_{25}$ & 0.597 & 0.816 & 1.413 & Antagonism \\
\hline
\end{tabular}

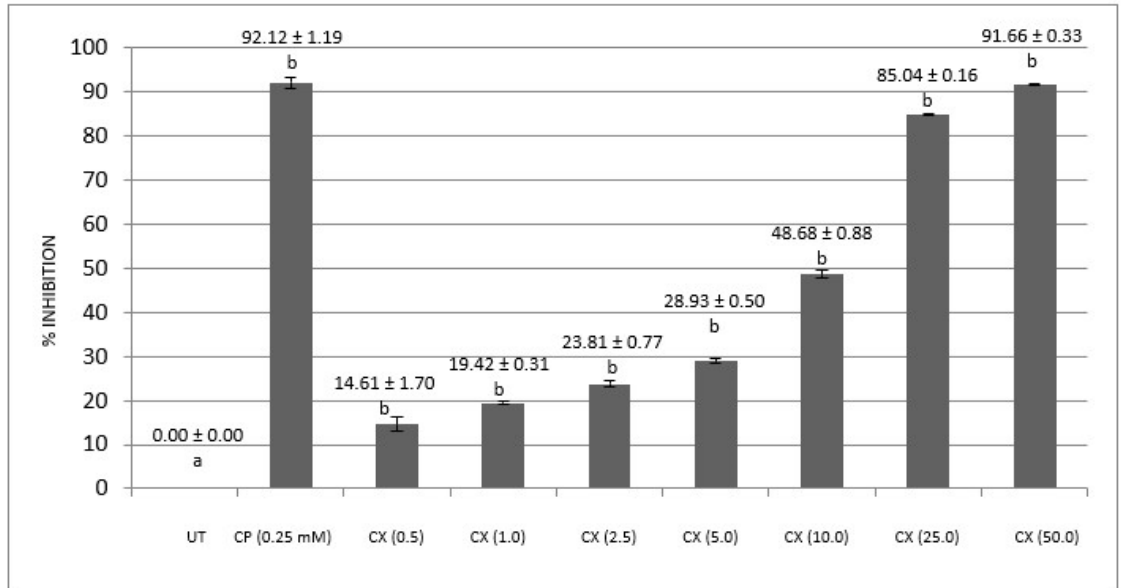

Figure 4. Proliferation inhibition (mean \pm SEM) activity of Cyclophosphamide (CX) (mM) against normal hepatocyte cell line (WRL 68). Cisplatin (CP) as a positive control. Bars with different letters denoted that the mean values were significantly different between treatments and untreated control (ANOVA posthoc Tukey, p $<0.05$ ). 


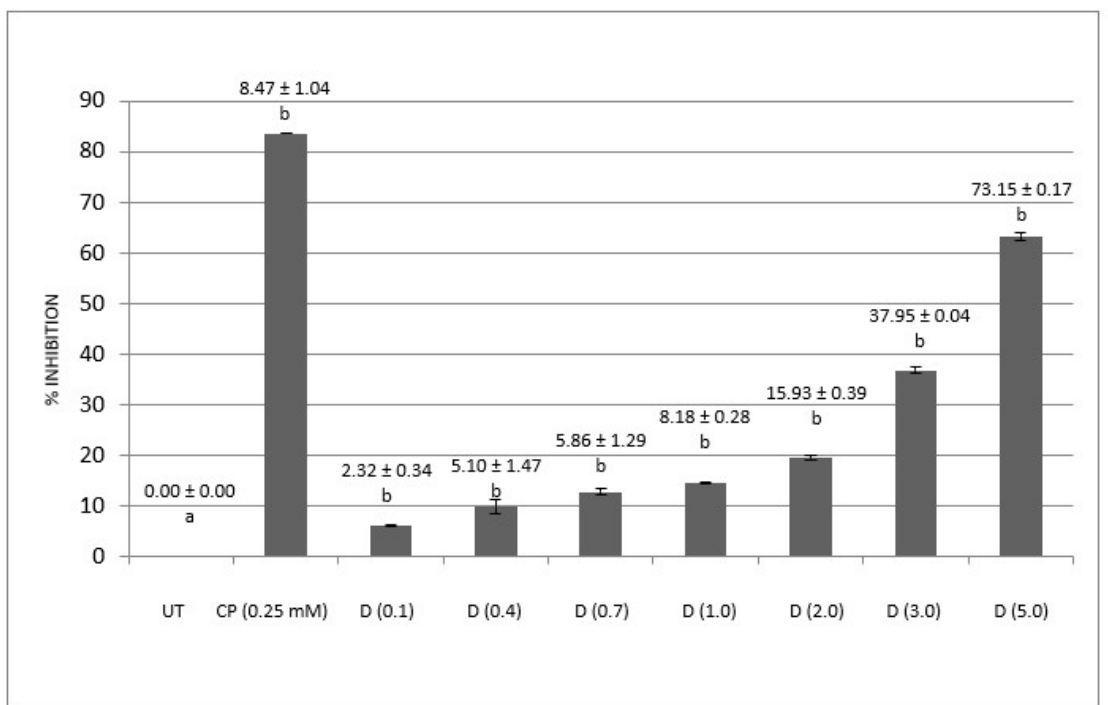

Figure 5. Proliferation inhibition (mean \pm SEM) activity of $C$. nutans ethanolic extract (D) $(\mathrm{mg} / \mathrm{mL})$ against normal hepatocyte cell line (WRL 68). Cisplatin (CP) as a positive control. Bars with different letters denoted that the mean values were significantly different between treatments and untreated control (ANOVA posthoc Tukey, $p<0.05$ )

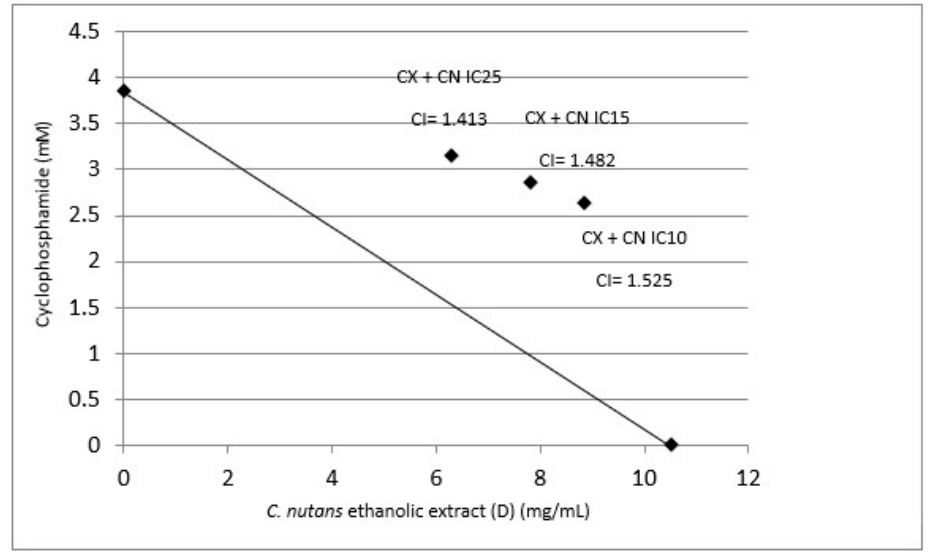

Figure 6. Isobologram of combination treatment of $C$. nutans ethanolic extract (D) and cyclophosphamide against normal hepatocyte cell line (WRL 68)

The effect of combination treatment of ethanolic extract (D) and cyclophosphamide on WRL 68 (normal liver) cell line was evaluated using MTT assay. Dose-response curve for a single treatment of cyclophosphamide and ethanolic extract (D) shown in Figure 4 and Figure 5, respectively. $\mathrm{IC}_{10}, \mathrm{IC}_{15}$, and $\mathrm{IC}_{50}$ value of single treatment of ethanolic extract (D) and single treatment of cyclophosphamide on WRL 68 (normal liver) cell line were derived and tabulated in Table 2 and Table 3 respectively. Combination treatments were conducted at concentration $\mathrm{IC}_{10}$ and $\mathrm{IC}_{15}$. The combination indexes (CI) were calculated, and the CI values as listed in Table 4. The combination treatment of ethanolic extract (D) and cyclophosphamide resulted in an antagonistic effect as the CI values were above than one. In the isobologram constructed as illustrated in Figure 6, the plots were falling above the line of additivity, which also indicated antagonism.

\section{DISCUSSION}

For aqueous extract, the decoction method was chosen to mimic traditional herbal tea preparation in herbal medicine. Preparation of ethanolic extract involved the sonication process and solvent removal, and both extracts resulted in dried powdered form after lyophilization. There are many factors affecting the yield of extraction, such as $\mathrm{pH}$ of the aqueous sample, solvent type and polarity, extraction time, number of extraction batch, and also chemical constituents of the sample (Mokrani \& Madani, 2016) 
It was found that the decoction process did not significantly decrease TPC of extract $\mathrm{C}$. This is because simple heating reportedly cannot cleave covalently bound phenolic compounds. Heating at $150^{\circ} \mathrm{C}$ for $30 \mathrm{~min}$ decreased the total phenolic content for onion varieties. On the other hand, heating caused a significant decrease in the TFC level as flavonoids to contain C-glycoside bonds and exist as dimers and oligomers, and heating or boiling results in hydrolysis of C-glycosides bonds (Sharma et al., 2015). Apart from temperature, solvent polarity does affect the phenolic content of the extracts. Ethanol is an effective solvent to extract polyphenols, flavonoids, alkaloids, and sterols while water dissolved glycosides as well as alkaloids (Galanakis et al., 2013). Phenols preference to polar protic solvents such as ethanol and methanol is due to the formation of hydrogen bonding between hydroxyl groups of the alcohol and oxygen atom in the phenol molecules (Vuong et al., 2014).

The extraction yield obtained for aqueous extract may occur due to its high carbohydrates content that is undetectable by UV-VIS spectra. In addition, apart from the favourable polarity of ethanol in the recovery of flavonoid compounds, the sonication process in ethanolic extraction might contribute to a greater amount of flavonoids identified in the ethanolic extract as reflected in the chromatogram. Sonication assists the destruction of cell walls thus enhancing better contact and interaction between plant material and solvent inside out. At low temperature, sonication improves the extractability of compounds by the solvent (Annegowda et al., 2011).

From the antiproliferative activity screening on a panel of cell lines, it was found that the ethanolic extract (D) did not exhibit the strong antiproliferative activity against all cell lines. According to the National Cancer Institute (NCI), a crude extract that exhibits an $\mathrm{IC}_{50}$ value $<20 \mu \mathrm{g} /$ $\mathrm{mL}$ can be considered as an active anticancer agent. This finding is supported by a previous study (Ng et al., 2018), that reported 50, 70 and $100 \%$ ethanol extract of C. nutans did not affect endothelial viability regardless of its concentrations up to $100 \mu \mathrm{g} / \mathrm{ml}$ even with prolonged treatment time from 24 to 72 hours. The antiproliferative activity of ethanolic extract (D) is the highest against MCF7 (breast cancer) and the lowest against CRL2522 (normal fibroblast) cell line. On WRL 68 (normal liver) and $\mathrm{HaCaT}$ (keratinocyte) the extract showed moderate inhibition of proliferation. This indicates that the ethanolic extract of $C$. nutans displayed tumor-specific antiproliferative activity in comparison to normal cells. The previous study suggested that the mechanism of action that responsible for antitumor activity of phenolic compounds include generation of the intolerable amount of $\mathrm{H}_{2} \mathrm{O}_{2}$ by polyphenols which induce cell apoptosis as well as prevention of cancer cell growth by inducing oxidative stress within the cell via neutralization of free radicals and scavenging reactive oxygen species (ROS) (Malta et al., 2013).

However, in the literature, a low correlation between TPC and antiproliferative activity in some plant extracts was reported (Tauchen et. al., 2016). Another study also could not find a clear correlation between TPC and antiproliferative activity of extract thus suggested in vitro tumor cell proliferation inhibition cannot be justified solely by the concentration of phenolic or flavonoid compounds because other phytochemical constituents of the extract might contribute a vital role in its antiproliferative activity (Malta et. al., 2013). Water-soluble portion of $C$. nutans stems and leaves extracts is rich in C-glycosyl flavones that were successfully isolated in the previous study, which include schaftoside, vitexin, isovitexin, orientin, isoorientin, and isomollupentin 7-Ob- glucopyranoside. These flavones might be as well responsible for the antiproliferative activity of $C$. nutans (Sakdarat et al., 2009).

Although the polar extracts of C. nutans were reported to have low antiproliferative activity, patients that undergo chemotherapy treatment still consume plant product such as $C$. nutans tea as complementary treatment without knowing its effects on chemotherapy. Drug-herb interactions may affect drug efficacy in several ways, potentially result in an antagonistic, additive, or synergistic effect. As a prodrug, cyclophosphamide undergoes metabolism by hepatic cytochrome P450 isozymes through the activation process by 4-hydroxylation pathway generating 4-hydroxycyclophosphamide that forms cytotoxic phosphoramide mustard as well as byproduct acrolein (Chen et al., 2004). The mechanism of antagonistic interaction between $C$. nutans ethanolic extract (D) and cyclophosphamide on WRL 68 (normal liver) cell line is not known. However, alteration of the CYP450 enzyme activity or expression could affect the efficacy of the drug treatment. A previous study reported that flavonoids contained in grapefruit juice inhibit CYP 450 , bind as a substrate to the enzyme system, and disrupt drug bioavailability (Say et al., 2017). Since C. nutans ethanolic extract contains high flavonoids level, it could potentially interact with CYP 450 enzymes of the cell line that may have affected metabolism and activation of the drug.

\section{CONCLUSION}

In conclusion, this study suggested that there was a potential antagonistic drug-herb posed by $C$. nutans ethanolic extract, which could impair the efficacy of cyclophosphamide treatment. Further investigation should be done in vivo and clinical research models to support these in vitro data.

E-ISSN 2477-0612 


\section{REFERENCES}

Alam, A., Ferdosh, S., Ghafoor, K., Hakim, A., Juraimi, A. S., Khatib, A., \& Sarker, Z. I. (2016). Clinacanthus nutans: A review of the medicinal uses, pharmacology and phytochemistry. Asian Pacific Journal of Tropical Medicine, 9(4), 402-409.

Al-Manhel, A. J., \& Niamah, A. K. (2015). Effect of aqueous and alcoholic plant extracts on inhibition of some types of microbes and causing spoilage of food. Journal of Nutrition \& Food Sciences, S5.

Annegowda, H. V., Bhat, R., Min-Tze, L., Karim, A. A., \& Mansor, S. M. (2011). Influence of sonication treatments and extraction solvents on the phenolics and antioxidants in star fruits. Journal of Food Science and Technology, 49(4), 510-514.

Aziz, A. \& Jack, R. (2015). Total phenolic content and antioxidant activity in Nypa fruticans extracts. Journal of Sustainability Science and Management, 10(1), 8791.

Bohlooli, S., Jafari, N., \& Jahed, S. (2012). Cytotoxic Effect of freeze-dried extract of Ecballium elaterium fruit on gastric adenocarcinoma (AGS) and esophageal squamous cell carcinoma (KYSE30) cell lines. Journal of Gastrointestinal Cancer,43(4), 579-583.

Cadena-Herrera, D., Lara, J. E., Ramírez-Ibañez, N. D., López-Morales, C. A., Pérez, N. O., Flores-Ortiz, L. F., $\&$ Medina-Rivero, E. (2015). Validation of three viablecell counting methods: Manual, semi-automated, and automated. Biotechnology Reports, 7, 9-16.

Chelyn, J. L., Omar, M. H., Yousof, S. A. M., Ranggasamy, R., Wasiman, M. I., and Ismail, Z. (2014). Analysis of flavone C-glycosides in the leaves of Clinacanthus nutans (Burm. f.) Lindau by HPTLC and HPLC-UV/DAD. The Scientific World Journal, 1-6.

Chen, C. S., Lin, J. T., Goss, K. A., He, Y. A., Halpert, J. R., \& Waxman, D. J. (2004). Activation of the anticancer prodrugs cyclophosphamide and ifosfamide: identification of cytochrome P450 2B enzymes and site-specific mutants with improved enzyme kinetics. Molecular Pharmacology, 65(5), 1278-1285.

Chikezie, P. C., \& Ojiako, O. A. (2015). Herbal Medicine: Yesterday, Today and Tomorrow. Alternative \& Integrative Medicine, 04(03).

Chin, J. H., Akowuah, G. A., Sabu, M. C., \& Khalivulla, S. I. (2014). Sub-Acute (28 days) toxicity study of methanol leaves extract of Clinacanthus nutans in rats. International Journal of Pharmacy, 4(2), 61-69.

Desai, A., Qazi, G., Ganju, R., El-Tamer, M., Singh, J., Saxena, A., Bedi, Y. S., Taneja, S. \& Bhat, H. (2008). Medicinal plants and cancer chemoprevention. Current Drug Metabolism, 9, 581-91.

Emadi, A., Jones, R. J., \& Brodsky, R. A. (2009). Cyclophosphamide and cancer: golden anniversary. Nature Reviews Clinical Oncology, 6(11), 638-647.

Fasinu, P. S., Bouic, P. J., \& Rosenkranz, B. (2012). An overview of the evidence and mechanisms of herbdrug interactions. Frontiers in Pharmacology, 3, 1-19.

Galanakis, C., Goulas, V., Tsakona, S., Manganaris, G., \& Gekas, V. (2013). A knowledge base for the recovery of natural phenols with different solvents. International Journal of Food Properties, 16(2), 382-396.

Hu, Z., Yang, X., Chi, L. H., Yung, C. S., Wan, W. S. H., Chan, E. \& Duan, W. \& Koh, H. L., \& Zhou, S. (2005). Herb-Drug Interactions: A Literature Review. Drugs. 65. 1239-82.

Kalita, Pallab \& Barman, T.K. \& Pal, Tapas \& Kalita, Ramen. (2013). Estimation of total flavonoids content (TFC) and antioxidant activities of methanolic whole plant extract of Biophytum sensitivum Linn. Journal of Drug Delivery and Therapeutics. 3.

Malta, L. G., Tessaro, E. P., Eberlin, M., Pastore, G. M., \& Liu, R. H. (2013). Assessment of antioxidant and antiproliferative activities and the identification of phenolic compounds of exotic Brazilian fruits. Food Research International, 53(1), 417-425.

Meijerman, I., Beijnen, J. H., \& Schellens, J. H. (2006). Herb-drug interactions in oncology: focus on mechanisms of induction. The Oncologist, 11(7), 742752 .

Mokrani, A., \& Madani, K. (2016). Effect of solvent, time and temperature on the extraction of phenolic compounds and antioxidant capacity of peach (Prunus persica L.) fruit. Separation and Purification Technology, 162, 68-76.

Ng, C. T., Fong, L. Y., Tan, J. J., Rajab, N. F., Abas, F., Shaari, K., Yong, Y. K. (2018). Water extract of Clinacanthus nutans leaves exhibits in vitro, ex vivo and in vivo anti-angiogenic activities in endothelial cell via suppression of cell proliferation. BMC Complementary and Alternative Medicine, 18(1). 
Norfazlina, M. N., Farida Zuraina, M. Y., Rajab, N. F., Mohd Nazip, S., Rumiza, A. R., Suziana Zaila, C. F. \& Florinsiah, L. (2014). In vitro cytotoxicity effects of single and combination Nigella sativa and Zingiber zerumbet extracts on human myeloid leukemia (HL60) cells and its mode of cell death. Journal of Applied Pharmaceutical Science, 4(05), 51-55.

Quah, S. Y., Chin, J. H., Akowuah, G. A., Khalivulla, S. I., Yeong, S. W., \& Sabu, M. C. (2017). Cytotoxicity and cytochrome P450 inhibitory activities of Clinacanthus nutans. Drug Metabolism and Personalized Therapy, $32(1)$.

Raja-Lexshimi, R. G., Oranye, N. O., Ho, S. E., Zuraida, J., \& Zulkifli, S. Z. (2013). Complementary and alternative medicine use among breast cancer patients in a tertiary hospital in Malaysia. Malaysian Journal of Public Health Medicine, 13(1), 11-19.

Sakdarat, S., Shuyprom, A., Pientong, C., Ekalaksananan, T., \& Thongchai, S. (2009). Bioactive constituents from the leaves of Clinacanthus nutans Lindau. Bioorganic \& Medicinal Chemistry, 17(5), 1857-1860.

Say, A., Ayar, A., \& Çakir, D. (217). Interaction Between Grapefruit Juice and Drugs. Acta Physica Polonica A, 132(3-II), 1030-1031.
Sharma, K., Ko, E. Y., Assefa, A. D., Ha, S., Nile, S. H., Lee, E. T., \& Park, S. W. (2015). Temperature-dependent studies on the total phenolics, flavonoids, antioxidant activities, and sugar content in six onion varieties. Journal of Food and Drug Analysis, 23(2), 243-252.

Su, M., Yu, T., Zhang, H., Wu, Y., Wang, X., \& Li, G. (2016). The antiapoptosis effect of glycyrrhizate on HepG2 cells induced by hydrogen peroxide. Oxidative Medicine and Cellular Longevity, 1-9.

Tauchen, J., Bortl, L., Huml, L., Miksatkova, P., Doskocil, I., Marsik, P., \& Kokoska, L. (2016). Phenolic composition, antioxidant and antiproliferative activities of edible and medicinal plants from the Peruvian Amazon. Revista Brasileira De Farmacognosia, 26(6), 728-737.

Vuong, Q., Hirun, S., Phillips, P., Chuen, T., Bowyer, M., Goldsmith, C., \& Scarlett, C. (2014). Fruitderived phenolic compounds and pancreatic cancer: perspectives from Australian native fruits. Journal of Ethnopharmacology, 152(2), 227-242.

Wargovich, M. J., Hollis, D. M., \& Zander, M. E. (2001). Herbals and Cancer Prevention. Functional Foods \& Nutraceuticals in Cancer Prevention, 237-262. 